\title{
Comparison of median and ulnar sensory nerve action potentials in the diagnosis of the carpal tunnel syndrome
}

\author{
S. C. LOONG AND C. S. SEAH \\ From the Medical Unit, Thomson Road General Hospital, Singapore
}

SUMMARY Recording of median and ulnar digital sensory nerve action potentials in normal subjects showed that the ratio of the median (index finger) to ulnar (little finger) potential amplitude $\vec{\circ}$ was consistently greater than one. In 15 patients with the carpal tunnel syndrome (seven bilateral) this ratio was found to be less than one for all but two of the 22 clinically affected hands, including $\vec{\omega}$ three of the four hands with a normal motor latency to threshold stimulation and four of the five? hands with a normal sensory conduction. It is concluded that the estimation of the ratio of the $\frac{5}{8}$ median to ulnar sensory potential amplitude is a sensitive test in the diagnosis of the carpal tunnel $\omega$ syndrome and is particularly useful in those patients who show a normal motor latency and sensory conduction.

Since the first description of the carpal tunnel syndrome (Brain, Wright, and Wilkinson, 1947), various techniques have been employed in the diagnosis of this condition. These currently include the measurement of distal motor latency (Simpson, 1956; Preswick, 1963) and the estimation of digital sensory conduction and amplitude (Gilliatt and Sears, 1958). While the diagnostic value of these methods is considerably enhanced by their combined application there still remains a group of patients, particularly those with minor, intermittent symptoms, who escape confirmation (Preswick, 1963; Fullerton and Gilliatt, 1965).

In the course of establishing normal conduction values for the authors' laboratory, it was observed that the amplitude of the 'median' digital sensory nerve action potential recorded at the wrist upon stimulation of the index finger was consistently greater than that of the 'ulnar' potential evoked by stimulation of the little finger of the same hand. This prompted the authors to investigate the probable disturbance of this relationship between the median and ulnar sensory potentials and its diagnostic significance in the carpal tunnel syndrome.

\section{METHODS}

The 15 patients used in this study were referred for electromyography with a clinical diagnosis of carpal tunnel syndrome. In seven the condition was bilateral; thus 22 clinically affected hands were examined. All t patients were female with an age range of 31 to 60 years. All of them gave a typical history of the syndrome with intermittent paraesthesia occurring spontaneously night or after use of the affected hand. None had a*y underlying disease such as diabetes. One patient (case $\mathbb{Q}$ ) was in the eighth month of her pregnancy when she pre- $\overrightarrow{0}$ sented. The relevant clinical data are summarized in Table 1.

All examinations were performed in a room with a constant ambient temperature of 23 to $25^{\circ} \mathrm{C}$. Surface electrodes were used for stimulation and recording and $\overline{0}$ the overall technique was essentially similar to that previously described (Dawson, 1956; Gilliatt and Sears, $\mathbb{D}$ 1958; Preswick and Jeremy, 1964). The index finger was stimulated for the median nerve and the little finger for 0 the ulnar nerve; great care was taken to prevent spread 3 of stimulus to the adjacent digits by covering them with a non-conducting adhesive plaster, as it was found that a spread of stimulus through contact of stimulating electrodes with the adjacent digits could significantly increase the size of the sensory potentiai in some in-: dividuals. The electrical stimulus, with a duration of 0.13 to $0.4 \mathrm{msec}$ and an amplitude up to $200 \mathrm{~V}$, was delivered by two Devices isolated stimulators. The muscle and $O$ nerve action potentials were amplified by a Tektronix $₹$ type 122 preamplifier and displayed for Polaroid photo-을 graphy on a Tektronix type 564B storage oscilloscope. For the purpose of estimation of sensory conduction velocity, the sensory latencies were measured from the stimulus artefact to the onset of the first negative deflection. $N$ However, sensory latencies to the peak of the main (negative) deflection were also recorded. The amplitudes 
TABLE 1

CLINICAL DETAILS AND ELECTROPHYSIOLOGICAL FINDINGS IN PATIENTS

\begin{tabular}{|c|c|c|c|c|c|c|c|c|c|c|c|c|c|c|}
\hline \multicolumn{7}{|c|}{ Clinical data } & \multicolumn{8}{|c|}{ Electrophysiological findings } \\
\hline \multirow{2}{*}{$\begin{array}{l}\text { Sex } \\
\text { and } \\
\text { age } \\
\text { yrs. }\end{array}$} & \multirow[t]{2}{*}{$\begin{array}{c}\text { Right } \\
\text { Left }\end{array}$} & \multirow{2}{*}{$\begin{array}{c}\text { Duration } \\
\text { of } \\
\text { symptoms } \\
(y r .)\end{array}$} & \multicolumn{2}{|c|}{ Symptoms } & \multicolumn{2}{|c|}{ Signs } & \multicolumn{2}{|c|}{$\begin{array}{c}\text { Median motor } \\
\text { latency }\end{array}$} & \multicolumn{4}{|c|}{ Median sensory potential } & \multirow{2}{*}{$\begin{array}{c}\text { Ulnar } \\
\text { sensory } \\
\text { amplitude } \\
(\mu V)\end{array}$} & \multirow{2}{*}{$\begin{array}{c}\text { Median } \\
\text { ulnar } \\
\text { sensory } \\
\text { amplitude } \\
\text { ratio }\end{array}$} \\
\hline & & & $\begin{array}{c}\text { Par- } \\
\text { aesthesia }\end{array}$ & $\begin{array}{c}\text { Weak- } \\
\text { ness }\end{array}$ & Sensory & $\begin{array}{l}\text { Motor } \\
(A P B)\end{array}$ & $\begin{array}{c}\text { Threshold } \\
\text { stim. } \\
\text { (msec) }\end{array}$ & $\begin{array}{c}\text { Supramax. } \\
\text { stim. } \\
\text { (msec) }\end{array}$ & $\begin{array}{c}\text { Amplitude } \\
(\mu V)\end{array}$ & $\begin{array}{l}\text { Latency } \\
\text { to peak } \\
\text { (msec) }\end{array}$ & $\begin{array}{l}\text { Latency } \\
\text { to onset } \\
(\mathrm{msec})\end{array}$ & $\begin{array}{c}\text { Conduction } \\
\text { velocity } \\
(\mathrm{m} / \mathrm{sec})\end{array}$ & & \\
\hline \multirow[t]{2}{*}{ F 40} & $\mathbf{R}$ & $2 / 12$ & + & - & $\div$ & - & 6.9 & $4 \cdot 4$ & $6 \cdot 0$ & $4 \cdot 0$ & $2 \cdot 9$ & 38 & $16 \cdot 5$ & 0.4 \\
\hline & $\mathbf{L}$ & $2 / 12$ & + & - & $\dot{t}$ & - & $5 \cdot 1$ & $3 \cdot 9$ & $10 \cdot 5$ & $3 \cdot 1$ & $2 \cdot 5$ & 46 & $22 \cdot 5$ & 0.5 \\
\hline \multirow[t]{2}{*}{ F 42} & $\overrightarrow{\mathbf{R}}$ & $6 / 12$ & + & - & + & + & $6 \cdot 7$ & $5 \cdot 1$ & $8 \cdot 0$ & $4 \cdot 2$ & $3 \cdot 2$ & 34 & $22 \cdot 5$ & 0.4 \\
\hline & $\mathbf{L}$ & $6 / 12$ & + & - & + & + & $6 \cdot 0$ & $5 \cdot 2$ & $18 \cdot 0$ & $3 \cdot 8$ & $2 \cdot \overline{9}$ & 38 & $19 \cdot 5$ & 0.9 \\
\hline \multirow[t]{2}{*}{ F 50} & $\mathbf{R}$ & 2 & + & + & - & + & 6.4 & $3 \cdot 5$ & 10.5 & 3.0 & $2 \cdot 4$ & 48 & $11 \cdot 3$ & 0.9 \\
\hline & $\mathbf{L}$ & 2 & + & + & - & $T$ & $5 \cdot 2$ & $4 \cdot 7$ & $16 \cdot 5$ & $3 \cdot 4$ & $2 \cdot 5$ & 42 & $19 \cdot 5$ & 0.9 \\
\hline F 59 & $\mathbf{R}$ & 1 & + & - & - & - & 11.0 & $6 \cdot 3$ & 3.8 & $5 \cdot 5$ & $4 \cdot 6$ & 25 & 19.0 & 0.2 \\
\hline F 45 & $\mathbf{R}$ & 1 & + & - & - & - & $5 \cdot 7$ & $5 \cdot 1$ & $16 \cdot 5$ & 3.7 & 2.9 & 38 & $22 \cdot 5$ & $0 . \overline{7}$ \\
\hline F 37 & $\mathbf{R}$ & 1 & + & - & - & - & 6.8 & $5 \cdot 3$ & $13 \cdot 5$ & $2 \cdot 4$ & $1 \cdot 8$ & 50 & 18.0 & 0.8 \\
\hline F 37 & $\mathbf{R}$ & $6 / 12$ & + & + & - & + & 5.0 & 3.4 & 16.5 & $2 \cdot 8$ & $2 \cdot 3$ & 48 & $24 \cdot 0$ & 0.7 \\
\hline F 60 & $\mathbf{R}$ & 2 & $-t$ & + & - & + & 6.0 & $5 \cdot 5$ & 4.0 & $4 \cdot 5$ & $3 \cdot 3$ & 36 & $10 \cdot 0$ & 0.4 \\
\hline \multirow[t]{2}{*}{ F 35} & $\mathbf{R}$ & $3 / 12$ & + & + & - & + & $7 \cdot 0$ & $4 \cdot 7$ & 8.0 & $4 \cdot 4$ & $3 \cdot 2$ & 36 & $16 \cdot 5$ & 0.5 \\
\hline & L & $3 / 12$ & + & + & - & + & 4.0 & 3.6 & 18.0 & $3 \cdot 2$ & $2 \cdot 8$ & 45 & 16.5 & $1 \cdot 1$ \\
\hline F 37 & $\mathbf{R}$ & 1 & + & - & - & - & $5 \cdot 7$ & $5 \cdot 1$ & 15.0 & 3.9 & 3.0 & 38 & 16.5 & 0.9 \\
\hline F 37 & $\mathbf{L}$ & $3 / 52$ & + & - & + & - & 6.0 & $4 \cdot 4$ & 0 & - & - & - & $18 \cdot 5$ & - \\
\hline F 31 & L & 1 & + & - & + & + & $7 \cdot 4$ & $6 \cdot 3$ & 0 & - & - & - & 15 & - \\
\hline \multirow[t]{2}{*}{ F 42} & $\overline{\mathbf{R}}$ & 4 & + & - & - & - & $4 \cdot 3$ & $3 \cdot 8$ & $11 \cdot 3$ & $3 \cdot 3$ & $2 \cdot 8$ & 42 & 16.5 & 0.9 \\
\hline & L & 4 & + & - & - & - & $5 \cdot 5$ & $4 \cdot 2$ & 12 & $4 \cdot 1$ & $3 \cdot 4$ & 35 & 13.5 & 0.9 \\
\hline \multirow[t]{2}{*}{ F 45} & $\overline{\mathbf{R}}$ & $3 / 12$ & + & - & + & - & $5 \cdot 2$ & $3 \cdot 3$ & 16.5 & 3.9 & $3 \cdot 2$ & 30 & 18.6 & 0.9 \\
\hline & $\mathbf{L}$ & $3 / 12$ & + & - & + & - & 6.4 & $4 \cdot 8$ & 0 & - & - & - & 18.0 & - \\
\hline \multirow[t]{2}{*}{ F 43} & $\mathbf{R}$ & 1 & + & - & t & - & $6 \cdot 1$ & $5 \cdot 6$ & $10 \cdot 5$ & $4 \cdot 4$ & $3 \cdot 5$ & 33 & $14 \cdot 3$ & 0.7 \\
\hline & & 1 & + & - & $T$ & - & $5 \cdot 2$ & $4 \cdot 7$ & $13 \cdot 5$ & $4 \cdot 2$ & $3 \cdot 3$ & 36 & $10 \cdot 5$ & $1 \cdot 3$ \\
\hline \multicolumn{7}{|c|}{ mal controls: Mean \pm 1 SD } & $\begin{array}{r}4 \cdot 36 \pm \\
0 \cdot 41 \\
(3 \cdot 4-5 \cdot 1)\end{array}$ & $\begin{array}{c}3.67 \pm \\
0.38 \\
(3.1-4.6)\end{array}$ & $\begin{array}{r}28.55 \pm \\
10.05 \\
(9-48)\end{array}$ & $\begin{array}{c}2 \cdot 82 \pm \\
0 \cdot 30 \\
(2 \cdot 2-3 \cdot 6)\end{array}$ & $\begin{array}{c}2 \cdot 16 \pm \\
0.23 \\
(1 \cdot 1-2 \cdot 8)\end{array}$ & $\begin{array}{r}52 \cdot 3 \pm \\
4 \cdot 1 \\
(44-59)\end{array}$ & $\begin{array}{c}18.98 \pm \\
5.45 \\
(7 \cdot 5-33)\end{array}$ & $\begin{array}{r}1.51 \pm \\
0.36 \\
(1 \cdot 1-2.4)\end{array}$ \\
\hline
\end{tabular}

of the sensory potentials were measured from peak to peak; at least five successive maximum action potentials were recorded (Figure) and if there was any variation, the average of their amplitudes was taken. Apart from sensory studies, motor responses evoked by threshold as well as supramaximal stimulation at the wrist were recorded from the abductor pollicis brevis muscle for motor latency measurement.

Similar studies were performed on 30 healthy female subjects with an age range of 30 to 60 years.

\section{RESULTS}

CONTROL OBSERVATIONS ON HEALTHY SUBJECTS The results for the control hands are given in Table 2. The overall findings for the sensory potentials are in agreement with those reported by others.

The ratio of action potential amplitudes of the median (index finger) to ulnar (little finger) sensory nerves was greater than unity for all control hands, with a range of $1 \cdot 1$ to $2 \cdot 4$.

The motor latencies with threshold stimulation varied in different individuals from 3.4-5.1 msec with a mean of $4 \cdot 36 \mathrm{msec}(\mathrm{SD} \pm 0.41)$. With supramaximal stimulation, the range was 3.1 to $4.6 \mathrm{msec}$ with a mean of $3.67 \mathrm{msec}$ (SD \pm 0.38 ). As these values were obtained with surface electrodes no strict comparison could be made with those by Preswick (1963).

PATIENTS WITH CARPAL TUNNEL SYNDROME The results of the patient group are given in Table 1 . As is necessary when considering individual cases, the criterion of abnormality is that the value should lie outside the normal range.

Motor latency with supramaximal stimulation was abnormal in only 13 out of 22 hands, whereas that

TABLE 2

RESULTS FOR CONTROL HANDS COMPARED WITH TWO CONTROL SERIES

\begin{tabular}{|c|c|c|c|c|}
\hline & $\begin{array}{l}\text { Median } \\
\text { sensory } \\
\text { velocity } \\
(\mathrm{m} / \mathrm{sec})\end{array}$ & $\begin{array}{l}\text { Median } \\
\text { sensory } \\
\text { latency } \\
\text { (msec) }\end{array}$ & $\begin{array}{c}\text { Median } \\
\text { sensory } \\
\text { amplitude } \\
(\mu V)\end{array}$ & $\begin{array}{c}\text { Ulnar } \\
\text { sensory } \\
\text { amplitude } \\
(\mu V)\end{array}$ \\
\hline $\begin{array}{l}\text { Present } \\
\text { series }\end{array}$ & $\begin{array}{c}44-59 \\
52 \cdot 3 \pm 4 \cdot 1^{*}\end{array}$ & $2 \cdot 2-3 \cdot 6$ & $9-48$ & $7 \cdot 5-33$ \\
\hline $\begin{array}{l}\text { Gilliatt and } \\
\text { Sears (1958) }\end{array}$ & N.A. $\dagger^{\prime}$ & $2 \cdot 5-4 \cdot 0$ & $9-45$ & $8-28$ \\
\hline $\begin{array}{l}\text { Preswick } \\
\text { (1964) }\end{array}$ & $\begin{array}{c}43-60 \\
50 \cdot 2 \pm 4 \cdot 8\end{array}$ & NA & NA & NA \\
\hline
\end{tabular}

*Mean \pm 1 SD. †Not available. 


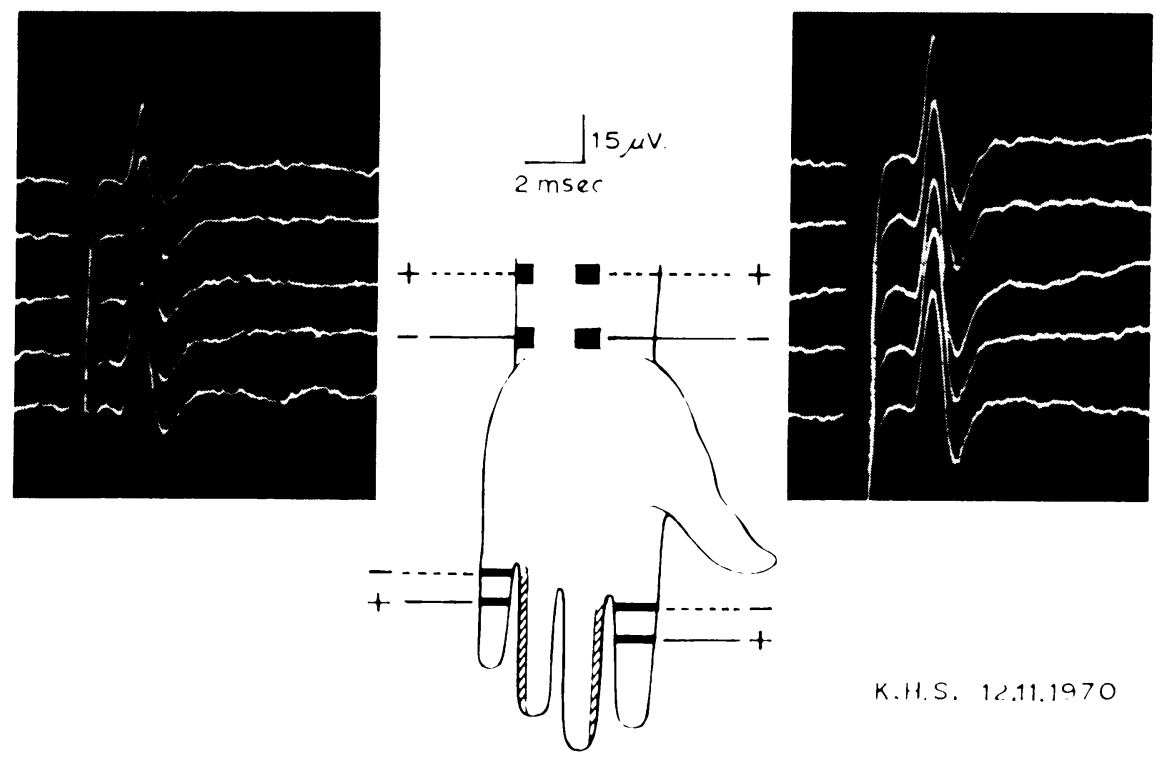

FIGURE Normal sensory nerve action potentials recorded from median and ulnar nerve trunks at the wrist in a healthy subject.

with threshold stimulation was abnormal in 18 out of 22 hands.

Median sensory nerve action potentials were absent in three hands. However, in the remaining hands only five had a sensory action potential with amplitude below the lower limit of normal. This clearly showed the limited diagnostic value of measuring absolute amplitude of sensory action potentials.

In the 19 hands in which median sensory action potentials were present, 12 had an abnormally prolonged sensory latency whether measurement was made to the onset or to the peak of the negative deflection. A slightly greater number of hands (14 out of 19) showed an abnormal result when sensory conduction was estimated in terms of metres per second. The amplitude ratio of the median (index finger) to ulnar (little finger) sensory action potential was below the lower limit of 1.1 in 17 out of the 19 hands; these included three of the four hands with a normal motor latency to threshold stimulation (cases $1-\mathrm{L}, 7,9-\mathrm{L}$, and $13-\mathrm{R}$ ) and four of the five hands with a normal sensory conduction (cases 1-L, 3-R, 6, 7, and 9-L). However, only two (cases $1-\mathrm{L}$ and 7 ) of these 17 hands had both a normal motor latency and sensory conduction. That these two hands did not represent misdiagnoses was supported by their typical clinical picture and by their motor latencies and sensory conduction being at the lower limit of normal. The two hands in which the median/ulnar sensory ratio did not fall below the lower limit of normal were both the clinically less affected left hands of right-handed individuals (cases 9 and 15) with a bilateral syndrome.

The percentage of abnormal results obtained wit the various diagnostic techniques is shown i Table 3.

\section{DISCUSSION}

The measurement of motor latency to supramaximal stimulation in the diagnosis of the carpal tunnel syndrome was first described by Simpson (1956). Although this remains the most convenient diagnostic test, its lack of sensitivity has been a recognized drawback. Simpson (1956) found an increased latency in 11 of 15 subjects with a clinical diagnosis of the syndrome. Similarly, in an unselected series of 95 consecutive cases with a diagnosis of suspected carpal tunnel syndrome, Thomas (1960) was able to demonstrate an abnormal latency to supramaximal stimulation in only two-thirds of them. The modified method with threshold stimulation by Preswick (1963) is a more sensitive diagnostic procedure (Fullerton and Gilliatt, 1965) and this has been further confirmed in the present study employing only surface electrodes.

While sensory conduction is expected to be altered in those cases with predominantly sensory symptoms, the diagnostic value of its estimation 
TABLE 3

RESULTS WITH VARIOUS DIAGNOSTIC TECHNIQUES

\begin{tabular}{|c|c|c|c|c|c|c|}
\hline & $\begin{array}{c}\text { Motor latency } \\
(\text { threshold })\end{array}$ & $\begin{array}{c}\text { Motor latency } \\
\text { (supramax.) } \\
(\%)\end{array}$ & $\begin{array}{c}\text { Median sensory } \\
\text { size } \\
(\%)\end{array}$ & $\begin{array}{c}\text { Median sensory } \\
\text { latency } \\
(\%)\end{array}$ & $\begin{array}{c}\text { Median sensory } \\
\text { velocity } \\
(\%)\end{array}$ & $\begin{array}{c}\text { Median/ulnar } \\
\text { sensory } \\
\text { size } \\
(\%)\end{array}$ \\
\hline $\begin{array}{l}\text { Present series } \\
\text { Thomas }(1960) \\
\text { Preswick (1963) } \\
\text { Gilliatt and Sears (1958) }\end{array}$ & $\frac{82}{86}$ & $\begin{array}{l}59 \\
63 \\
62 \\
-\end{array}$ & $\frac{36}{55}$ & $\frac{63}{-}$ & $\begin{array}{l}74 \\
- \\
-\end{array}$ & $\frac{90}{-}$ \\
\hline
\end{tabular}

is lessened somewhat by its wide normal range, while comparison with contralateral median conduction is not possible in patients with a bilateral syndrome. Similarly, owing to considerable variation in sensory amplitude in different individualssuch variation being as great with needle as with surface electrodes (Buchthal and Rosenfalck, 1966) - the measurement of the median sensory action potential amplitude per se cannot be expected to have great diagnostic sensitivity, particularly in the early cases.

Gilliatt and Sears (1958) noted in their controls that sensory action potentials recorded from the ulnar nerve at the wrist were generally smaller than those from the median nerve at the wrist. However, no specific mention was made of their relationship in individual subjects and of prevention of spread of stimulus to adjacent digits. The present study shows that the amplitude of the median sensory action potential recorded at the wrist is consistently greater than that of the ulnar action potential in the same hand of normal subjects when the stimulus is confined to the index and the little finger, respectively. This consistency was observed despite possible experimental errors in peak-to-peak measurement and variation of responses secondary to difference in distance from the nerves. That this median (index) to ulnar (little finger) sensory action potential amplitude ratio is greater than one is to be expected in view of the fact that the index finger is the larger and functionally more important digit and presumably carries more sensory fibres; Buchthal and Rosenfalck (1966), for example, have shown that the sensory threshold is significantly lower for the index finger than for the other digits. It is noteworthy that the median/ulnar sensory action potential amplitude ratio was reduced to below one ('reversed') in all but two of the 22 clinically affected hands, including three of the four hands with a normal motor latency to threshold stimulation and four of the five hands with a normal sensory conduction. This indicates that, as a diagnostic procedure, the estimation of the median/ulnar sensory action potential amplitude ratio has a greater sensitivity than that of motor latency measurement or sensory conduction estimation alone. However, it suffers from the disadvantage that this sensitivity is expected to be reduced when it is performed on patients with an associated ulnar nerve lesion in the same hand.

The recognition of the carpal tunnel syndrome is important as disabling symptoms can be readily relieved by hydrocortisone injection or retinacular section. The diagnosis of the syndrome is easy when clinical involvement is limited to the distribution of the median nerve in the hand but becomes difficult when sensory symptoms are absent or spread to involve ulnar digits or to the elbow, or even up to the shoulder. In the latter instances, electrodiagnostic methods become particularly important. However, any one of the techniques discussed above may give a normal result despite clinical evidence to the contrary. Hence, more than one procedure may have to be employed. The present study indicates that the measurement of the ratio of median to ulnar sensory action potential amplitude is a useful addition to the battery of tests available for the diagnosis of the carpal tunnel syndrome and would be particularly of value in those patients who show a normal motor latency and sensory conduction.

We are grateful to the Lions Club (Host) International, Singapore, for their generosity which made possible the setting up of the EMG laboratory. We wish to thank the orthopaedic surgeons of the Outram Road General Hospital who referred all the patients used in this study.

\section{REFERENCES}

Brain, W. R., Wright, A. D., and Wilkinson, M. (1947). Spontaneous compression of both median nerves in the carpal tunnel. Lancet, 1, 277-282.

Buchthal, F., and Rosenfalck, A. (1966). Evoked action potentials and conduction velocity in human sensory fibres. Brain Res., 3, 1-122.

Dawson, G. D. (1956). The relative excitability and conduction velocity of sensory and motor nerve fibres in man. J. Physiol. (Lond.), 131, 436-451. 
Fullerton, P. M., and Gilliatt, R. W. (1965). The carpaltunnel syndrome. Lancet, $2,241$.

Gilliatt, R. W., and Sears, T. A. (1958). Sensory nerve action potentials in patients with peripheral nerve lesions. $J$. Neurol. Neurosurg. Psychiat., 21, 109-118.

Preswick, G. (1963). The effect of stimulus intensity on motor latency in the carpal tunnel syndrome. J. Neurol. Neurosurg. Psychiat., 26, 398-401.
Preswick, G., and Jeremy, D. (1964). Subclinical polyneuropathy in renal insufficiency. Lancet, 2, 731-732.

Simpson, J. A. (1956). Electrical signs in the diagnosis of carpal tunnel and related syndromes. J. Neurol. Neurosurg. Psychiat., 19, 275-280.

Thomas, P. K. (1960). Motor nerve conduction in the carpal tunnel syndrome. Neurology (Minneap.), 10, 1045-1050.

\section{The October 1971 Issue}

\section{THE OCTOBER 1971 ISSUE CONTAINS THE FOLLOWING PAPERS}

Judgment of spatial orientaiion in patients with focal brain damage ENNIO DE RENZI, PIERO FAGLIONI, and GIUSEPPE SCOTTI

Disturbances of the body schema in relation to language impairment and hemispheric locus of lesion J. SAUGUET, A. L. BENTON, and H. HÉCAEN

Psychiatric aspects in Parkinsonism treated with L-dopa ANTÓNIO R. DAMÁSIO, JOÃo LOBO-ANTUNES, and CARLOS MACEDO

Musclesilent period in Parkinson's disease D. C. HIGGINS, N. H. HAIDRI, and A. J. WILBOURN

Mechanical properties of dystrophic mouse muscle J. B. HARRIS and P. WILSON

Miniature end-plate potentials in neuromuscular disease: an electrophysiological investigation of motor-point muscle biopsies J. HAYNES

Serum creatine kinase studies in the detection of carriers of Duchenne dystrophy R. C. HUGHES, DOROTHY C. PARK, MARY E. PARSONS, and M. D. O'BRIEN

Myasthenia gravis occurring in twins T. NAMBA, M. S. SHAPIRO, N. G. BRUNNER, and D. GROB

Prognosis of pituitary adenomas with arteriographic abnormal vascularization D. A. ROTH, E. J. FERRIS, and U. TOMIYASU

Angioblastic meningioma with hepatic metastasis CAROL K. PETITO and ROBERT S. PORRO

Ependymal cyst of the spinal cord: case report HUGH $\mathbf{S}$. WISOFF and NITYA R. GHATAK

Altered thermal sensitivity in injured and demyelinated nerve FLOYD A. DAVIS and SAMUEL JACOBSON

Orthostatic hypotension and the Holmes-Adie syndrome R. H. JOHNSON, D. L. MCLELLAN, and D. R. LOVE
Effect of folic acid by mouth on cerebrospinal fluid homovanillic acid and 5-hydroxyindoleacetic acid concentration RICHARD HUNTER, JOANNA BARNES, G. CURZON, B. D. KANTAMANENI, and CATHERINE DUNCAN

Common carotid ligation for the treatment of ruptured posterior communicating aneurysms R. V. JEFFREYS and A. E. HOLMES

Response of cerebrospinal fluid pressure to hyperbario oxygenation T. HAYAKAWA, N. KANAI, R. KURODA, R YAMADA, and H. MOGAMI

Vascular responses to acute intracranial hypertensio S. S. HAYREH and J. EDWARDS

Non-uniform response of regional cerebral blood flow to stimulation of cervical sympathetic nerve TAKENORO YAMAGUCHI and ARTHUR G. WALTZ

Idiopathic polyneuritis: serial studies of nerve and immune functions MICHAEL P. MCQUILLEN

Human flexor reflexes BHAGWAN T. SHAHANI and ROBERT R. YOUNG

Radiofrequency cordotomy for the relief of spasticity in decerebrate cats DANIEL SORIANO and RICHARD HERMAN

Scoliosis: a rare manifestation of intrinsic tumours of the spinal cord in children M. BANNA, G. W. PEARCE, and R. ULDALL

Clustering of the morphological components of perinatal telencephalic leucoencephalopathy ALAN LEVITON and FLOYD H. GILLES

Activation of the electroencephalogram with intravenous Brietal (methohexitone): the findings in 100 cases JOHN GUMPERT and RONALD PAUL

Book reviews

Copies are still available from the PUBLISHING MANAGER BRITISH MEDICAL ASSOCIATION, TAVISTOCK SQUARE, LONDON, WC1H 9JR, price $£ 1 \cdot 50$ 